\title{
Ionic and Enzymatic Multiple-Crosslinked Nanogels for Drug Delivery
}

\author{
Qian Tao*D, Julong Zhong, Rui Wang and Yuzhu Huang \\ School of Chemistry and Materials Science, Ludong University, Yantai 264025, China; \\ zhongjulong@163.com (J.Z.); wangrcherry@163.com (R.W.); hyuzhu741@sina.com (Y.H.) \\ * Correspondence: taoqian@ldu.edu.cn
}

\begin{abstract}
Both ionic and enzymatic crosslink are efficient strategies for constructing network materials of high biocompatibility. Here chitosan was modified firstly and then crosslinked by these two methods for complementary advantages. The preparation methods and ionic crosslinkers can regulate the size and uniformity of the multiple-crosslinked nanogels. The multiple-crosslinked nanogels with the smallest size and the best uniformity was selected for the drug delivery. The drug-loading content and encapsulation efficiency were up to 35.01 and $66.82 \%$, respectively. Their release behaviours are correlated with the $\mathrm{pH}$ value and the drug dosage. In general, the lower $\mathrm{pH}$ value and the lower drug dosage promoted the drug release. With the assistance of several kinetic models, it is found that drug diffusion plays a preponderant role in drug release, while polymer relaxation has a subtle effect. The multiple-crosslink resulting from ionic compounds and enzymes may provide a new perspective on developing novel biocompatible materials.
\end{abstract}

Keywords: multiple-crosslinked nanogel; ionic crosslink; enzymatic crosslink; drug delivery; natural polymeric materials

Citation: Tao, Q.; Zhong, J.; Wang, R.; Huang, Y. Ionic and Enzymatic Multiple-Crosslinked Nanogels for Drug Delivery. Polymers 2021, 13, 3565. https://doi.org/10.3390/ polym13203565

Academic Editors: Ankit K. Rochani, John Eisenbrey and Gagan Kaushal

Received: 22 September 2021

Accepted: 13 October 2021

Published: 15 October 2021

Publisher's Note: MDPI stays neutral with regard to jurisdictional claims in published maps and institutional affiliations.

\section{Introduction}

Natural polymeric materials are popular candidates for drug carriers due to their excellent biocompatibility and biodegradability. Many strategies have been devised to endow the drug carriers based on natural polymeric materials with extensive and advanced functions [1-3]. The stable and compact structures composed of natural polymers are generally desired. Various kinds of crosslinkers play vital roles in building these structures $[4,5]$. The chemical crosslinking reagents (e.g., dialdehyde) were introduced early and performed satisfactorily. However, the possible cytotoxicity [6] and strong covalent bonding brought by chemical crosslinkers impair the biocompatibility and biodegradability of natural polymeric materials. More attention has been paid to bio-friendly crosslinkers, such as ionic crosslinkers and enzymatic crosslinkers.

Ionic crosslinking is a mild reaction that is suitable for natural polymers [7-9]. Chitosan becomes a polycationic polymer in a solution of a $\mathrm{pH}$ value less than 6 . Thus it can be crosslinked by the anionic reagent, such as divalent sulphate $\left(\mathrm{SO}_{4}{ }^{2-}\right)$, trivalent phosphate $\left(\mathrm{PO}_{4}{ }^{3-}\right)$, and pentavalent tripolyphosphate (TPP). Ionic crosslinked materials often exhibit excellent biocompatibility and $\mathrm{pH}$ sensitivity, making them qualified for drug carriers [10]. The enzyme can catalyze the crosslinking of natural polymers efficiently. The amino acid residues on the gelatin chains are crosslinked rapidly with the catalysis of microbial transglutaminase (mTG) [11-13]. The phenol groups grafted on the natural polymers can be crosslinked in the presence of horseradish peroxidase (HRP) and $\mathrm{H}_{2} \mathrm{O}_{2}$ [14-16]. The enzymatic reactions occur fast and gently under the physiological environment. More significantly, the biocompatibility of enzymes is beyond doubt $[17,18]$.

However, the ionic crosslinked materials are hard to retain stable structures, and enzymatic crosslinked materials may degrade quickly. It is realized that the combined utilization may complement crosslinking methods for each other and obtain a material 
with optimized properties. The combinations of crosslinking methods have been reported in the studies of tissue engineering scaffolds $[19,20]$. For example, the interpenetrating polymer network (IPN) materials are composed of two different polymers crosslinked by two different methods [21]. The IPN hydrogels prepared by Lee et al. were composed of chitosan and poly (acrylic acid) [22]. The IPN hydrogels reported by Li et al. were composed of gelatin and alginate [23].

Nevertheless, one polymer multiple-crosslinked by several methods is more favourable as drug carriers with nanoscales because of the easier preparation and more controllable delicate structures. Here we crosslinked the same polymer by ionic and enzymatic crosslinkers coordinately to prepare nanogels whose structures were easily regulated. Their performances in a drug delivery were studied furthermore. The novel multiple crosslinking is expected to bring a new perspective for the drug carriers with natural polymer.

\section{Materials and Methods}

\subsection{Materials and Instruments}

Chitosan (the deacetylation degree $\geq 95 \%$ ), 1-(3-Dimethylaminopropyl)-3-ethylcarbodiimide hydrochloride (EDC-HCl), N-hydroxysuccinimide (NHS), Phloretic acid (PA), 2-(N-Morpholino)ethanesulfonic acid (MES), Sodium tripolyphosphate (TPP), and Sodium molybdate $\left(\mathrm{Na}_{2} \mathrm{MoO}_{4}\right)$ and horseradish peroxidase (HRP) $(>300 \mathrm{U} / \mathrm{mg}$, lyophilized powder) were all purchased from Aladdin Biochemical Technology Co., Ltd. (Shanghai, China) and used as received. 5-Fluorouracil (5-FU) was obtained from Macklin Biochemical Co., Ltd. (Shanghai, China). Nuclear magnetic resonance (NMR) spectrometer (AVANCE NEO, $500 \mathrm{MHz}$, Bruker) and Fourier transform infrared (FTIR, MAGNA550, Nicolet) was used for structural analysis. Nanoparticle size analyzer (Nano-ZS90, Malvern) was used to determine the size of the nanogels. UV-Vis spectrophotometer (T6, Persee) was used to determine the concentrations of 5-FU in the drug loading and release experiments.

\subsection{Synthesis of Phenolic Hydroxyl Modified Chitosan (MC)}

The phenolic hydroxyl group was conjugated to the amine group of chitosan in the presence of EDC/NHS. $1.28 \mathrm{~g}$ of chitosan was dissolved in $100 \mathrm{~mL}$ of a $0.5 \%$ acetic acid solution [24-26]. The $\mathrm{pH}$ value was adjusted to approximately 5.0 after complete dissolution. PA of $0.88 \mathrm{~g}, 0.93 \mathrm{~g}$ of NHS, and $1.52 \mathrm{~g}$ of EDC-HCl were dissolved in a $100 \mathrm{~mL}$ mixture of $\mathrm{N}, \mathrm{N}$-dimethylformamide (DMF) and deionized water $(v / v=3: 2)$. Then it was blended with a chitosan-acetic acid solution and kept at ambient temperature for $20 \mathrm{~h}$. The reaction mixture was dialyzed against deionized water for several days and then freeze-dried to obtain the modified chitosan (MC). ${ }^{1} \mathrm{H}$ NMR spectrum of $\mathrm{MC}$ in $\mathrm{D}_{2} \mathrm{O}$ was recorded at $500 \mathrm{MHz}$. FTIR spectra of $\mathrm{MC}$ and chitosan were recorded in the wavenumber range of $4000-400 \mathrm{~cm}^{-1}$ using $\mathrm{KBr}$ pressed disk technique.

\subsection{Preparation of Nanogels with TPP and HRP Multiple-Crosslinking}

The MC was dissolved in MES solutions for at least $24 \mathrm{~h}$, and the $\mathrm{pH}$ values were kept at 5.0. TPP and HRP were respectively dissolved at specific concentrations in advance. Then the chitosan nanogels were prepared according to the composition listed in Table 1. Besides the different TPP concentrations, different preparation methods were also employed. One method was adding the MC solution into the TPP solution first and then mixing it with the $\mathrm{HRP}$ and $\mathrm{H}_{2} \mathrm{O}_{2}$ solution. The other method was adding the MC solution into the TPP, HRP, and $\mathrm{H}_{2} \mathrm{O}_{2}$ mixed solution. All the solution mixing and the preparations of the nanogels were performed with mild electromagnetic stirring and stabilized at room temperature for $24 \mathrm{~h}$. 
Table 1. Composition of multiple-crosslinked nanogels with TPP and HRP.

\begin{tabular}{|c|c|c|c|c|}
\hline Sample & $\mathrm{MC}\left(\mathrm{mg} \mathrm{mL} \mathrm{L}^{-1}\right)$ & TPP (mg mL $\left.{ }^{-1}\right)$ & HRP ((U mL $\left.{ }^{-1}\right)$ & $\mathrm{H}_{2} \mathrm{O}_{2}(\mathrm{mM})$ \\
\hline $\mathrm{MC} / \mathrm{T} / \mathrm{H}-\mathrm{A} 1$ & 1.0 & 0.20 & 0.5 & 0.08 \\
\hline $\mathrm{MC} / \mathrm{T} / \mathrm{H}-\mathrm{A} 2$ & 1.0 & 0.10 & 0.5 & 0.08 \\
\hline $\mathrm{MC} / \mathrm{T} / \mathrm{H}-\mathrm{A} 3$ & 1.0 & 0.05 & 0.5 & 0.08 \\
\hline $\mathrm{MC} / \mathrm{T} / \mathrm{H}-\mathrm{A} 4$ & 1.0 & 0.04 & 0.5 & 0.08 \\
\hline $\mathrm{MC} / \mathrm{T} / \mathrm{H}-\mathrm{B} 1$ & 1.0 & 0.20 & 0.5 & 0.08 \\
\hline $\mathrm{MC} / \mathrm{T} / \mathrm{H}-\mathrm{B} 2$ & 1.0 & 0.10 & 0.5 & 0.08 \\
\hline $\mathrm{MC} / \mathrm{T} / \mathrm{H}-\mathrm{B} 3$ & 1.0 & 0.05 & 0.5 & 0.08 \\
\hline $\mathrm{MC} / \mathrm{T} / \mathrm{H}-\mathrm{B} 4$ & 1.0 & 0.04 & 0.5 & 0.08 \\
\hline
\end{tabular}

A: The crosslinking occurs with TPP first and then with HRP; B: The crosslinking occurs with TPP and HRP simultaneously.

\subsection{Preparation of Nanogels with $\mathrm{Na}_{2} \mathrm{MoO}_{4}$ and HRP Multiple Crosslinking}

The nanogels with $\mathrm{Na}_{2} \mathrm{MoO}_{4}$ and HRP were prepared according to the method above, and their composition was listed in Table 2.

Table 2. Composition of multiple-crosslinked nanogels with $\mathrm{Na}_{2} \mathrm{MoO}_{4}$ and HRP.

\begin{tabular}{|c|c|c|c|c|}
\hline Sample & $\mathrm{MC}\left(\mathrm{mg} \mathrm{mL}^{-1}\right)$ & $\mathrm{Na}_{2} \mathrm{MoO}_{4}\left(\mathrm{mg} \mathrm{mL}^{-1}\right)$ & HRP $\left(U \mathrm{~mL}^{-1}\right)$ & $\mathrm{H}_{2} \mathrm{O}_{2}(\mathrm{mM})$ \\
\hline $\mathrm{MC} / \mathrm{M} / \mathrm{H}-\mathrm{A} 1$ & 1.0 & 0.20 & 0.5 & 0.08 \\
\hline $\mathrm{MC} / \mathrm{M} / \mathrm{H}-\mathrm{A} 2$ & 1.0 & 0.10 & 0.5 & 0.08 \\
\hline $\mathrm{MC} / \mathrm{M} / \mathrm{H}-\mathrm{A} 3$ & 1.0 & 0.05 & 0.5 & 0.08 \\
\hline $\mathrm{MC} / \mathrm{M} / \mathrm{H}-\mathrm{A} 4$ & 1.0 & 0.04 & 0.5 & 0.08 \\
\hline $\mathrm{MC} / \mathrm{M} / \mathrm{H}-\mathrm{B} 1$ & 1.0 & 0.20 & 0.5 & 0.08 \\
\hline $\mathrm{MC} / \mathrm{M} / \mathrm{H}-\mathrm{B} 2$ & 1.0 & 0.10 & 0.5 & 0.08 \\
\hline $\mathrm{MC} / \mathrm{M} / \mathrm{H}-\mathrm{B} 3$ & 1.0 & 0.05 & 0.5 & 0.08 \\
\hline $\mathrm{MC} / \mathrm{M} / \mathrm{H}-\mathrm{B} 4$ & 1.0 & 0.04 & 0.5 & 0.08 \\
\hline
\end{tabular}

A: The crosslinking occurs with $\mathrm{Na}_{2} \mathrm{MoO}_{4}$ first and then with HRP; B: The crosslinking occurs with $\mathrm{Na}_{2} \mathrm{MoO}_{4}$ and HRP simultaneously.

\subsection{Measurement of the Nanogel Size}

The nanogel size was determined by a nanoparticle size analyzer with the appropriate dilution. Measurements of all the samples were repeated 3 times, and the hydrodynamic diameter distribution was recorded based on the scattered light intensity.

\subsection{Drug Loading}

5-FU was dissolved in MES solutions and subsequently mixed with the MC solution. The mass ratio of 5-FU to MC was 50, 100 and 150\%, respectively. These mixtures were used to prepare drug-loaded nanogels, referring to the method above. The solutions of nanogels were dialyzed against deionized water for $3 \mathrm{~h}$. Then the concentrations of 5-FU in dialysates were determined by UV-Vis spectrophotometer. The standard solutions of 5-FU were prepared in the concentrations of $2.5 \mathrm{mg} / \mathrm{L}, 5 \mathrm{mg} / \mathrm{L}, 7.5 \mathrm{mg} / \mathrm{L}, 10 \mathrm{mg} / \mathrm{L}, 12.5 \mathrm{mg} / \mathrm{L}$, respectively. The UV-Vis spectra of 5-FU solutions showed the highest absorption peak at $265 \mathrm{~nm}$, which was selected as the measuring wavelength to determine the standard curve of 5-FU. The standard calibration was repeated 3 times, and the $R^{2}$ of the standard curve were all more than 0.99 . The drug-loading content (DLC\%) and entrapment efficiency $(\mathrm{EE} \%)$ of the nanogels were calculated according to the reference [27].

\subsection{Drug Release}

The drug release in vitro was studied by UV-Vis spectrophotometer. The drug-loaded nanogels $(5 \mathrm{~mL})$ were dialyzed against $50 \mathrm{~mL}$ of MES solutions at $25^{\circ} \mathrm{C}$. The $\mathrm{pH}$ value of the MES solution was adjusted in advance to $5.5,6.5$ or 7.5 by adding hydrochloric acid or potassium hydroxide. A $3 \mathrm{~mL}$ portion of the dialysate was extracted at predetermined intervals to determine the concentration of the drug. At the same time, $3 \mathrm{~mL}$ of fresh MES 
solution was added to the dialysate. The experiments were performed in triplicate, and the results were expressed in terms of the cumulative drug release [28].

The kinetics of the 5-FU released from the nanogels was determined by fitting the release profiles to several theoretical models (including zero-order, first-order, Higuchi, Korsmeyer-Peppas, and Peppas-Sahlin models).

\section{Results and Discussion}

\subsection{Structural Characterization and Enzymatic Crosslinking of MC}

The ${ }^{1} \mathrm{H}$ NMR spectrum of MC (Supplementary Materials Figure S1) showed the chemical shifts of both PA groups and chitosan, proving that the phenolic hydroxyl was grafted on the chitosan. The chemical shifts at 6.76 and $6.44 \mathrm{ppm}$ corresponded to the aromatic protons of the phenolic group. The chemical shifts at 2.44 and $2.27 \mathrm{ppm}$ corresponded to the methylene protons of PA. The chemical shifts from 4.51 to $2.80 \mathrm{ppm}$ corresponded to the glucopyranose ring protons of chitosan. FTIR was also used to confirm the chemical structure (Figure S2). In the FTIR spectrum of chitosan, the bands at $3354 \mathrm{~cm}^{-1}$ (stretching vibrations of $-\mathrm{OH}$ and $-\mathrm{NH}_{2}$ in chitosan), at $1150 \mathrm{~cm}^{-1}$ (asymmetric stretching vibration of $\mathrm{C}-\mathrm{O}-\mathrm{C}$ bridge between glucopyranose rings), at $1024 \mathrm{~cm}^{-1}$ (stretching vibrations of glucopyranose ring) were observed. The FTIR spectrum of MC exhibited the bands attributing to the stretching vibration of $-\mathrm{OH}$ in the phenolic group $\left(3257 \mathrm{~cm}^{-1}\right)$, asymmetric stretching vibration of $\mathrm{C}-\mathrm{H}$ in the methylene of PA $\left(2920 \mathrm{~cm}^{-1}\right)$, and stretching vibration of $C-C$ in the phenolic group (1644-1514 $\left.\mathrm{cm}^{-1}\right)$.

The crosslinking of the MC under the enzymatic catalysis was verified. The MC solution was low-viscous and flowable before adding HRP, whereas the gel was formed soon after adding HRP (Figure 1). It proves that the phenolic hydroxyl groups were grafted with the chitosan chains, which linked to each other in the presence of HRP. Thus, a three-dimensional network was constructed. This enzymatic crosslinking was in line with expectations and ready for the preparation of multiple-crosslinked nanogels.
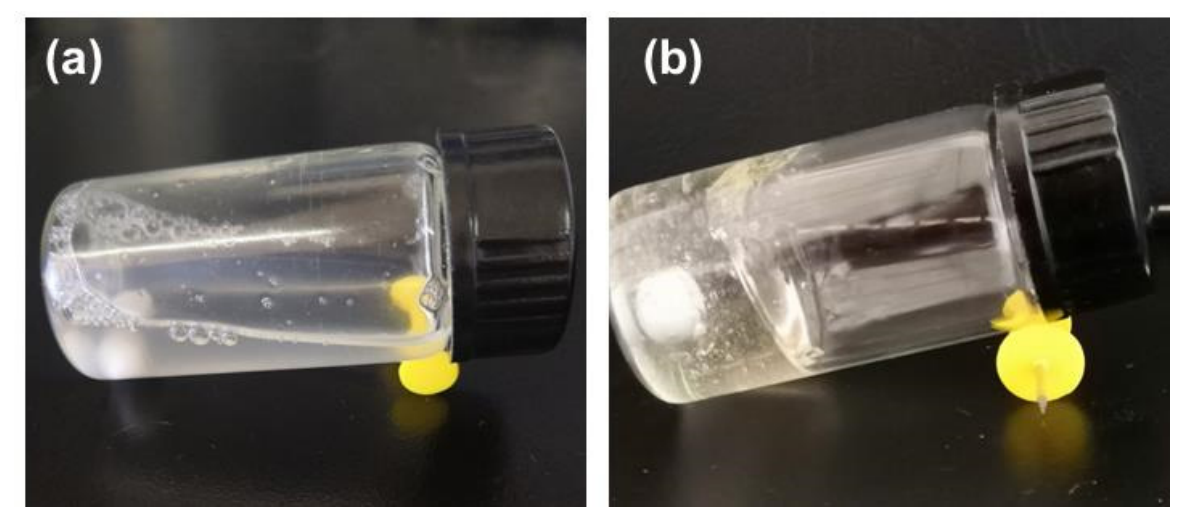

Figure 1. The MC solution before (a) and after (b) HRP-catalysed crosslinking. The concentrations of $\mathrm{MC}, \mathrm{HRP}$, and $\mathrm{H}_{2} \mathrm{O}_{2}$ are $10 \mathrm{mg} \mathrm{mL}^{-1}, 5 \mathrm{U} \mathrm{mL}^{-1}$, and $0.8 \mathrm{mM}$.

\subsection{Influences on the Preparations of Multiple-Crosslinked Nanogels}

Two methods were used to prepare the multiple-crosslinked nanogels, where the crosslinking occurred with the ionic crosslinker first and then with HRP (method A) or the crosslinking occurs with the ionic crosslinker and HRP simultaneously (method B). Besides, the nanogels prepared only with ionic crosslinkers were compared with them (Figure 2).

The different hydrodynamic diameters of the nanogels indicate that the HRP-involved nanogel generally has a smaller size because the extra crosslinking provided by HRP makes the chitosan networks more compact. Further comparing methods A and B shows that the nanogels prepared by method B were smaller than those prepared by method A. it is considered that the crosslinking of chitosan chains is more efficient when two types of crosslinkers coexist. It is tricky for HRP to catalyze in method A because the ionic crosslinking occurs first, making a part of the phenolic hydroxyl groups wrapped inside. 

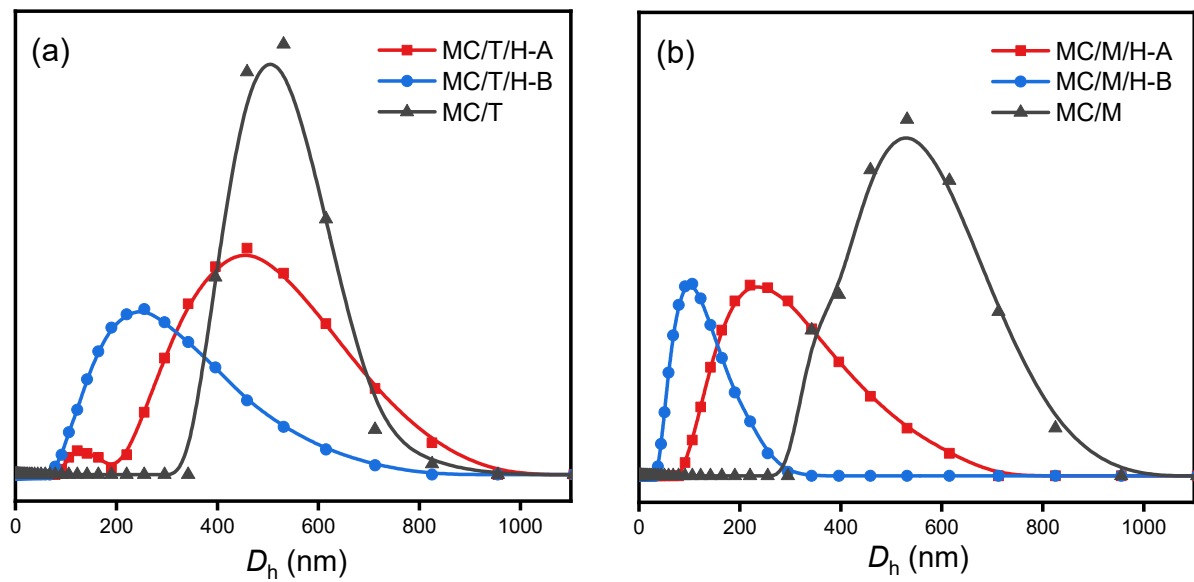

Figure 2. Hydrodynamic diameter distributions of multiple-crosslinked nanogels prepared with different methods. The concentrations of TPP (a) or $\mathrm{Na}_{2} \mathrm{MoO}_{4}(\mathbf{b})$ were $0.05 \mathrm{mg} \mathrm{mL}^{-1}$, respectively.

In addition to the method, the type of ionic crosslinker also significantly impacts the preparation of multiple-crosslinked nanogels. The multiple-crosslinked nanogels prepared with $\mathrm{Na}_{2} \mathrm{MoO}_{4}$ have a smaller size and narrower distribution, which is more competitive for drug delivery. The crosslinking efficiency depends on the ionic bonds between anions of the crosslinker and amino ions of the chitosan. TPP exists as a pentavalent anion, and $\mathrm{Na}_{2} \mathrm{MoO}_{4}$ exists as a divalent anion in solutions. TPP possesses more joinpoints than $\mathrm{Na}_{2} \mathrm{MoO}_{4}$ with the same mass. Hence more chitosan chains were linked with TPP rather than $\mathrm{Na}_{2} \mathrm{MoO}_{4}$, causing the larger nanogels.

Moreover, the concentrations of ionic crosslinkers have an apparent effect on the size of the multiple-crosslinked nanogels. The sizes of the nanogels decrease as the ion concentration decreases, shown in both methods A and B (Figure 3). The higher ion concentration provides more crosslinking points and thus increases the possibility of forming larger crosslinking structures. It is noted that the nanogels prepared by method B were all smaller than those prepared by method A in the case of four different concentrations.

(a)
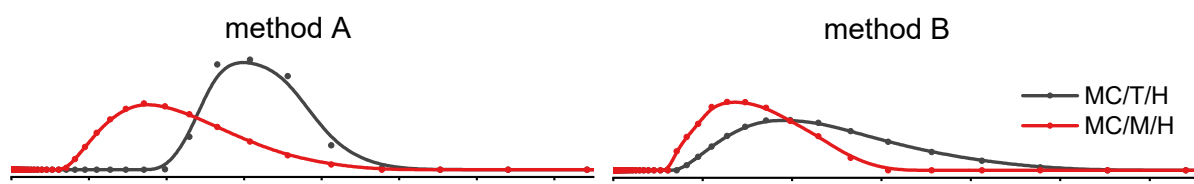

(b)
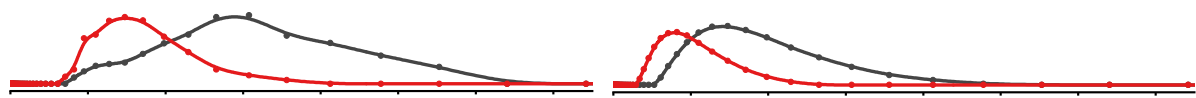

(c)
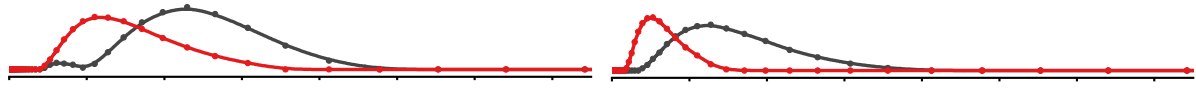

(d)
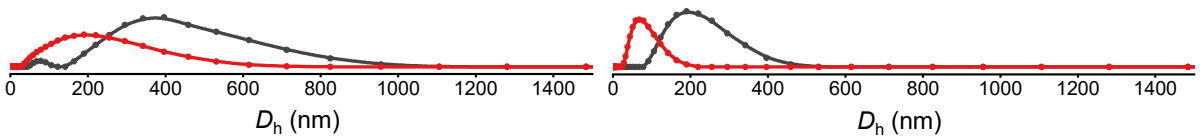

Figure 3. Hydrodynamic diameter distributions of multiple-crosslinked nanogels prepared with the method A and B. The concentrations of TPP or $\mathrm{Na}_{2} \mathrm{MoO}_{4}$ were 0.20 (a), 0.10 (b), 0.05 (c), $0.04(\mathbf{d}) \mathrm{mg} \mathrm{mL}^{-1}$, respectively.

Considering the above influences, the multiple-crosslinked nanogel labelled as $\mathrm{MC} / \mathrm{M} / \mathrm{H}-$ B4 was selected for the subsequent drug delivery experiments due to its smallest size and the best uniformity among all the samples. 


\subsection{Drug Loading in Multiple-Crosslinked Nanogels}

In the drug delivery experiments, 5-FU was selected as a model drug. 5-FU is a common anti-metabolism and anti-tumour drug, but it usually causes gastrointestinal discomfort when taken directly. Therefore, a sustained-release carrier is necessary to improve drug utilization and reduce the damage to healthy cells.

The drug-loading method determined by screening tests is to mix 5-FU firstly with MC rather than with crosslinkers. This method is feasible because the 5-FU could be dispersed evenly among the complex spatial conformation of chitosan longer chains, improving the loading efficiency of 5-FU in the network structures of nanogels (Figure 4a).

(a)

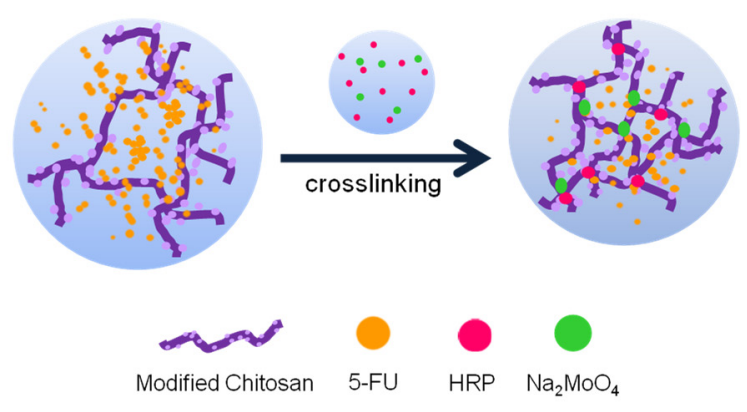

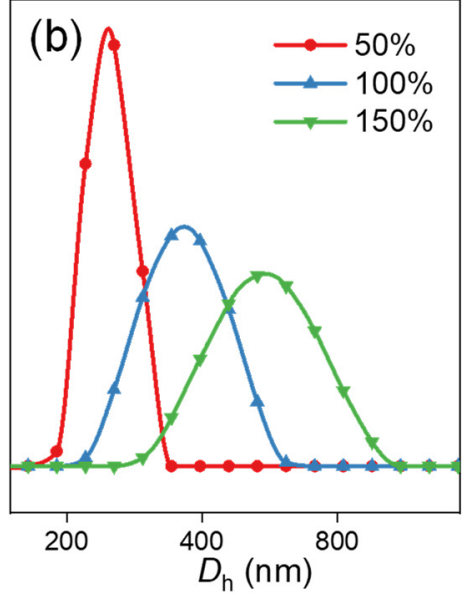

Figure 4. (a) Scheme of 5-FU loading in multiple-crosslinked nanogel; (b) Hydrodynamic diameter distributions of $\mathrm{MC} / \mathrm{M} / \mathrm{H}-\mathrm{B} 4$ nanogels with different 5-FU dosages.

The size and uniformity of the drug-loaded nanogels are necessary for the long-term circulation of drug carriers in the body. Here the influence of different drug dosages was studied (Figure $4 \mathrm{~b}$ ). With the increase of drug dosage from 50 to $150 \%$, the hydrodynamic diameters of 5-FU loaded nanogels increase, and the size distributions become wide.

The essential criteria for drug-loading experiments are drug-loading content (DLC) and entrapment efficiency (EE), listed in Table 3. The DLC increased from 23.55 to $35.01 \%$ with the drug dosage increase. However, the increase gets small when the dosage increases from 100 to $150 \%$. It is indicated that increasing the drug dosage would not be worthwhile because the DLC almost reached the maximum amount that the nanogels could withstand. The EE decreased with the drug dosage increase and reached $66.82 \%$ when the drug dosage was $50 \%$. Overall, increasing the drug dosage could achieve a higher DLC, but more 5-FU cannot be loaded in the carrier, resulting in a waste of drugs. The balance between the DLC and $\mathrm{EE}$ should be determined on the requirements of specific applications.

Table 3. The drug-loading content and entrapment efficiency of MC/M/H-B4 nanogels for 5-FU (all data are expressed as mean $\pm \mathrm{SD}, n=10$ ).

\begin{tabular}{cccc}
\hline & \multicolumn{3}{c}{$\boldsymbol{m}_{\mathbf{0}} / \boldsymbol{m} \mathbf{( \% )}$} \\
\cline { 2 - 4 } & $\mathbf{5 0}$ & $\mathbf{1 0 0}$ & $\mathbf{1 5 0}$ \\
\hline DLC (\%) & $23.55 \pm 4.68$ & $32.30 \pm 7.04$ & $35.01 \pm 5.19$ \\
EE (\%) & $66.82 \pm 7.92$ & $64.60 \pm 4.09$ & $58.35 \pm 8.66$ \\
\hline
\end{tabular}

$m_{0}$ and $m$ are the weight of 5-FU and $\mathrm{MC} / \mathrm{M} / \mathrm{H}-\mathrm{B} 4$ nanogels, respectively.

\subsection{Drug Release from Multiple-Crosslinked Nanogels}

Chitosan shows $\mathrm{pH}$ sensitivity due to the amino groups. Consequently, the release profiles of chitosan-derived drug carriers are generally impacted by the $\mathrm{pH}$ values. The 
influences of $\mathrm{pH}$ on drug release behaviours from MC/M/H-B4 nanogels were studied (Figure 5).
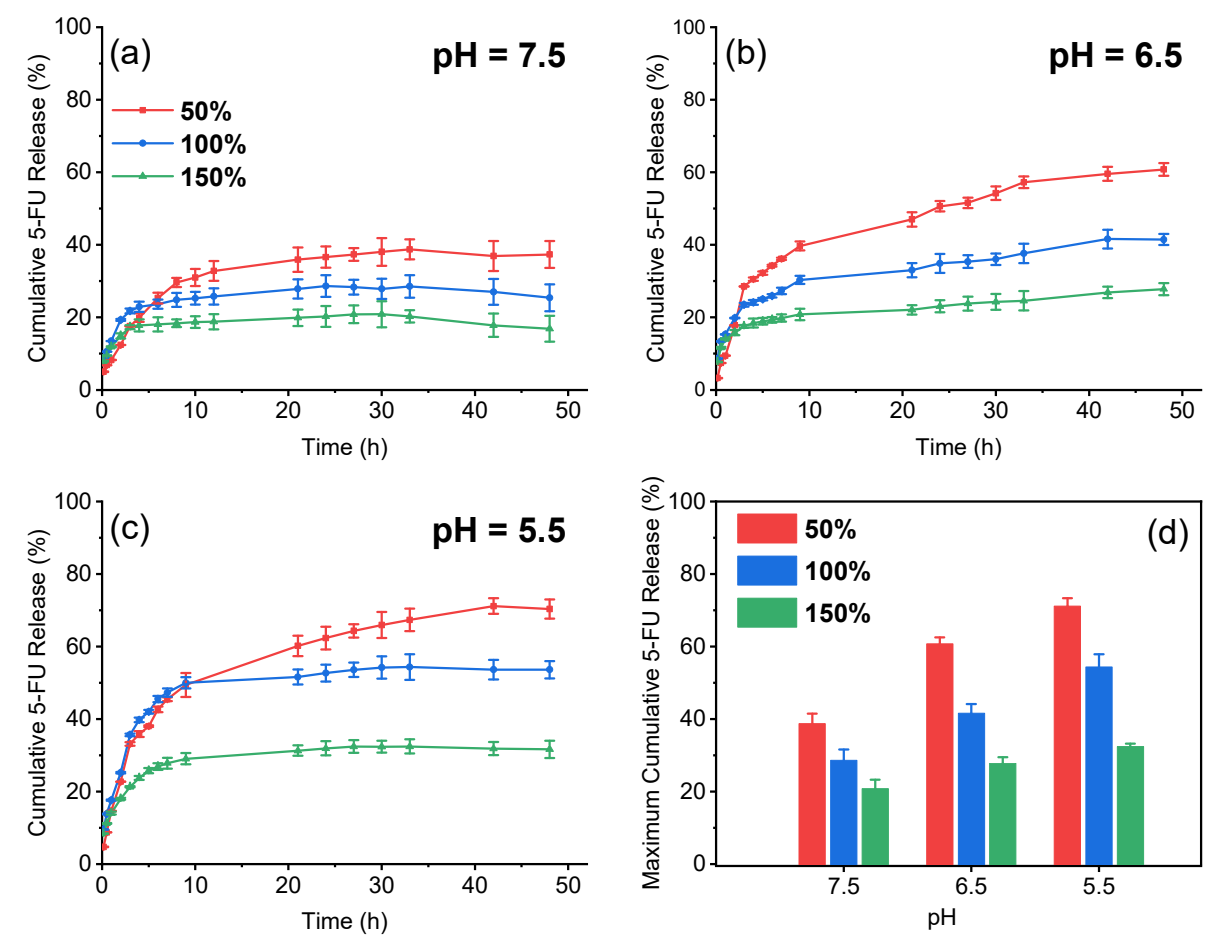

Figure 5. Release profiles of $\mathrm{MC} / \mathrm{M} / \mathrm{H}-\mathrm{B} 4$ nanogels $(\mathbf{a}-\mathbf{c})$ and the maximum cumulative 5-FU release from nanogels with different drug dosages at different $\mathrm{pH}$ values $(\mathbf{d})$.

The 5-FU release was slow in the first $30 \mathrm{~h}$ at $\mathrm{pH} 7.5$, and the maximum cumulative release was $38.7 \%$ (dosage of $50 \%$ ). The 5 -FU duration increased to $48 \mathrm{~h}$ at $\mathrm{pH} 6.5$, and the maximum cumulative release was $60.8 \%$ (dosage of $50 \%$ ). The fastest 5 -FU release occurred at $\mathrm{pH} 5.5$, and the maximum cumulative release was $71.2 \%$ (dosage of $50 \%$ ). It shows that the drug could be released from the $\mathrm{MC} / \mathrm{M} / \mathrm{H}-\mathrm{B} 4$ nanogels and be easier to leave at lower $\mathrm{pH}$ values. As the $\mathrm{pH}$ value decreases, the drug release becomes faster, and the maximum cumulative release increases.

The reasons for the $\mathrm{pH}$-responsive release were analyzed. The protonated chitosan chains are more stretched and bring looser networks, causing faster drug release at a lower $\mathrm{pH}$. However, 5-FU was also protonated in the acid medium and competed with chitosan. It is difficult for chitosan chains to maintain the loose structure when the 5-FU concentration increases. Therefore the two higher dosages groups' release at $\mathrm{pH} 5.5$ slowed down significantly after $20 \mathrm{~h}$.

It is also found that the drug release becomes quicker, and the maximum cumulative release increases with the drug dosage decrease at the three different $\mathrm{pH}$ levels. (Figure $5 \mathrm{~d}$ ). The path of drug diffusion is complicated due to the network structure. Thus the drug molecules are more difficult to arrive outside when the drug-loading content is higher.

Furthermore, several kinetic models were used to evaluate the drug release profiles for revealing the mechanism of drug release. The equations and parameters of the different models are listed in Table 4 [29-31]. The $R^{2}$ of Korsmeyer-Peppas and Peppas-Sahlin are higher than zero-order, first-order and Higuchi, indicating that Korsmeyer-Peppas and Peppas-Sahlin are adequate for describing the release behaviours. 
Table 4. Kinetic parameters of 5-FU release from $\mathrm{MC} / \mathrm{M} / \mathrm{H}-\mathrm{B} 4$ nanogels.

\begin{tabular}{|c|c|c|c|c|c|c|c|c|c|c|}
\hline Models & $\begin{array}{c}m_{0} / m \\
(\%)\end{array}$ & \multicolumn{3}{|c|}{$\mathrm{pH}=5.5$} & \multicolumn{3}{|c|}{$\mathrm{pH}=6.5$} & \multicolumn{3}{|c|}{$\mathrm{pH}=7.5$} \\
\hline \multirow{4}{*}{$\begin{array}{c}\text { Zero-order } \\
\quad F=k t\end{array}$} & & $R^{2}$ & & & $R^{2}$ & & & $R^{2}$ & & \\
\hline & 50 & 0.9108 & & & 0.8786 & & & 0.9365 & & \\
\hline & 100 & 0.8967 & & & 0.8655 & & & 0.7143 & & \\
\hline & 150 & 0.8902 & & & 0.7734 & & & 0.647 & & \\
\hline \multirow{4}{*}{$\begin{array}{l}\text { First-order } \\
F=1-e^{-k t}\end{array}$} & & $R^{2}$ & & & $R^{2}$ & & & $R^{2}$ & & \\
\hline & 50 & 0.9496 & & & 0.9081 & & & 0.9538 & & \\
\hline & 100 & 0.9314 & & & 0.8881 & & & 0.7322 & & \\
\hline & 150 & 0.9077 & & & 0.7902 & & & 0.6562 & & \\
\hline \multirow{4}{*}{$\begin{array}{l}\text { Higuchi } \\
F=k t^{0.5}\end{array}$} & & $R^{2}$ & & & $R^{2}$ & & & $R^{2}$ & & \\
\hline & 50 & 0.9856 & & & 0.9647 & & & 0.9874 & & \\
\hline & 100 & 0.9768 & & & 0.9661 & & & 0.8765 & & \\
\hline & 150 & 0.982 & & & 0.9149 & & & 0.8276 & & \\
\hline \multirow{4}{*}{$\begin{array}{c}\text { Korsmeyer-Peppas } \\
\qquad F=k t^{n}\end{array}$} & & $R^{2}$ & $n$ & & $R^{2}$ & $n$ & & $R^{2}$ & $n$ & \\
\hline & 50 & 0.9908 & 0.6106 & & 0.9798 & 0.6502 & & 0.9767 & 0.4823 & \\
\hline & 100 & 0.9849 & 0.4493 & & 0.9893 & 0.3026 & & 0.9536 & 0.2738 & \\
\hline & 150 & 0.9947 & 0.3302 & & 0.9687 & 0.2369 & & 0.9444 & 0.2199 & \\
\hline \multirow{4}{*}{$\begin{array}{l}\text { Peppas-Sahlin } \\
F=k_{1} t^{m}+k_{2} t^{2 m}\end{array}$} & & $R^{2}$ & $k_{1}$ & $k_{2}$ & $R^{2}$ & $k_{1}$ & $k_{2}$ & $R^{2}$ & $k_{1}$ & $k_{2}$ \\
\hline & 50 & 0.9947 & 0.3034 & -0.0286 & 0.9853 & 0.2361 & -0.0206 & 0.9851 & 0.1933 & -0.0208 \\
\hline & 100 & 0.9717 & 0.3067 & -0.0385 & 0.9809 & 0.1161 & -0.0094 & 0.9764 & 0.1333 & -0.0174 \\
\hline & 150 & 0.9901 & 0.1568 & -0.0194 & 0.9542 & 0.0686 & -0.0062 & 0.9565 & 0.0935 & -0.0132 \\
\hline
\end{tabular}

In all models, $F$ is the fraction mass of 5 -FU released at time $t$, and $k$ (or $\left.k_{1}, k_{2}\right)$ is the kinetic constant.

The diffusional release exponent $(n)$ of the Korsmeyer-Peppas model reveals the mechanism of drug release from porous hydrophilic polymers and is effective when the released drug is no more than $60 \%$. Moreover, the $K_{2}$ of the Peppas-Sahlin model represents the polymer relaxation's contribution to the drug release with no restriction on the drug release [32]. Therefore, a combination of these two models is optimal to analyze the chitosan-derived nanogels.

The $n$ values for the 100 and $150 \%$ dosage are less than 0.45 , indicating that these release mechanisms are Fickian diffusion. The $n$ values for a dosage of $50 \%$ are more than 0.45 and less than 0.89 , indicating a case II transport (erosion-controlled drug release) [33]. The $n$ values increase with $\mathrm{pH}$ decrease. It is considered that the hydrogen bonds between the chitosan and 5-FU are formed. The proportion of 5-FU that forms hydrogen bonds is more prominent with less dosage, and the lower $\mathrm{pH}$ is conducive to hydrogen bonding.

$K_{1}$ and $K_{2}$ of Peppas-Sahlin models respectively represent drug diffusion and polymer relaxation contributions to the drug release [34]. For all release profiles of 5-FU release from $\mathrm{MC} / \mathrm{M} / \mathrm{H}-\mathrm{B} 4$ nanogels, drug diffusion plays a preponderant role in the drug release rate, while polymer relaxation has a subtle effect on the release rate.

\section{Conclusions}

The ionic (TPP or $\mathrm{Na}_{2} \mathrm{MoO}_{4}$ ) and enzymatic (HRP) crosslinkers were employed to prepare the multiple-crosslinked chitosan nanogels. The size and uniformity of the multiple-crosslinked nanogels are influenced by preparation methods and types and concentrations of the ionic crosslinker. The multiple-crosslinked nanogels of small size and high uniformity were selected for the drug delivery. The multiple-crosslinked chitosan nanogels perform impressively on drug loading and controlled release. The drug-loading content and encapsulation efficiency are up to 35.01 and $66.82 \%$, respectively. Adjusting the $\mathrm{pH}$ value and the drug dosage could change the release rate and the maximum cumulative 
release from the multiple-crosslinked nanogels. Moreover, the evaluation of kinetic models explains the release mechanism under different conditions.

The ionic and enzymatic multiple-crosslinked nanogels positively impact biocompatibility and work well as drug carriers. The method developed in this study could provide new opportunities for biomedical applications of natural polymers.

Supplementary Materials: The following are available online at https:/ /www.mdpi.com/article/10 .3390 / polym13203565/s1, Figure S1: ${ }^{1} \mathrm{H}$ NMR spectrum of MC in $\mathrm{D}_{2} \mathrm{O}$ at $500 \mathrm{MHz}$, Figure S2. FTIR spectra of chitosan and MC.

Author Contributions: Conceptualization, Q.T.; methodology, J.Z. and Q.T.; sample preparation, data collection and analysis, J.Z. and R.W.; writing-original draft preparation, R.W. and Y.H.; writing - review and editing, Q.T.; project administration, Q.T. All authors have read and agreed to the published version of the manuscript.

Funding: This research was funded by the National Natural Science Foundation of China (Grant No. 51403096) and the Natural Science Foundation of Shandong, China (Grant No. ZR2014EMP003).

Institutional Review Board Statement: Not applicable.

Informed Consent Statement: Not applicable.

Data Availability Statement: Data is contained within the article.

Conflicts of Interest: The authors declare no conflict of interest.

\section{References}

1. Wang, W.; Liu, X.; Xie, Y.; Zhang, H.; Yu, W.; Xiong, Y.; Xie, W.; Ma, X. Microencapsulation using natural polysaccharides for drug delivery and cell implantation. J. Mater. Chem. 2006, 16, 3252. [CrossRef]

2. Nigmatullin, R.; Thomas, P.; Lukasiewicz, B.; Puthussery, H.; Roy, I. Polyhydroxyalkanoates, a family of natural polymers, and their applications in drug delivery. J. Chem. Technol. Biotechnol. 2015, 90, 1209-1221. [CrossRef]

3. Tong, X.; Pan, W.; Su, T.; Zhang, M.; Dong, W.; Qi, X. Recent advances in natural polymer-based drug delivery systems. React. Funct. Polym. 2020, 148, 104501. [CrossRef]

4. Luo, K.; Yang, Y.; Shao, Z. Physically crosslinked biocompatible silk-fibroin-based hydrogels with high mechanical performance. Adv. Funct. Mater. 2016, 26, 872-880. [CrossRef]

5. Liu, Y.; Zheng Shu, X.; Prestwich, G.D. Biocompatibility and stability of disulfide-crosslinked hyaluronan films. Biomaterials 2005, 26, 4737-4746. [CrossRef] [PubMed]

6. Berger, J.; Reist, M.; Mayer, J.M.; Felt, O.; Peppas, N.A.; Gurny, R. Structure and interactions in covalently and ionically crosslinked chitosan hydrogels for biomedical applications. Eur. J. Pharm. Biopharm. 2004, 57, 19-34. [CrossRef]

7. Gierszewska, M.; Ostrowska-Czubenko, J. Chitosan-based membranes with different ionic crosslinking density for pharmaceutical and industrial applications. Carbohydr. Polym. 2016, 153, 501-511. [CrossRef] [PubMed]

8. Liling, G.; Di, Z.; Jiachao, X.; Xin, G.; Xiaoting, F; Qing, Z. Effects of ionic crosslinking on physical and mechanical properties of alginate mulching films. Carbohydr. Polym. 2016, 136, 259-265. [CrossRef]

9. Kuo, C.K.; Ma, P.X. Ionically crosslinked alginate hydrogels as scaffolds for tissue engineering: Part 1. Structure, gelation rate and mechanical properties. Biomaterials 2001, 22, 511-521. [CrossRef]

10. Izzo, D.; Palazzo, B.; Scalera, F.; Gullotta, F.; lapesa, V.; Scialla, S.; Sannino, A.; Gervaso, F. Chitosan scaffolds for cartilage regeneration: Influence of different ionic crosslinkers on biomaterial properties. Int. J. Polym. Mater. Polym. Biomater. 2019, 68, 936-945. [CrossRef]

11. Gupta, D.; Santoso, J.W.; McCain, M.L. Characterization of gelatin hydrogels cross-linked with microbial transglutaminase as engineered skeletal muscle substrates. Bioengineering 2021, 8, 6. [CrossRef]

12. Chen, R.-N.; Ho, H.-O.; Sheu, M.-T. Characterization of collagen matrices crosslinked using microbial transglutaminase. Biomaterials 2005, 26, 4229-4235. [CrossRef] [PubMed]

13. McDermott, M.K.; Chen, T.; Williams, C.M.; Markley, K.M.; Payne, G.F. Mechanical properties of biomimetic tissue adhesive based on the microbial transglutaminase-catalyzed crosslinking of gelatin. Biomacromolecules 2004, 5, 1270-1279. [CrossRef]

14. Roberts, J.J.; Naudiyal, P.; Lim, K.S.; Poole-Warren, L.A.; Martens, P.J. A comparative study of enzyme initiators for crosslinking phenol-functionalized hydrogels for cell encapsulation. Biomater. Res. 2016, 20, 1-12. [CrossRef] [PubMed]

15. Lee, F.; Bae, K.H.; Kurisawa, M. Injectable hydrogel systems crosslinked by horseradish peroxidase. Biomed. Mater. 2015, 11, 14101. [CrossRef]

16. Kurisawa, M.; Chung, J.E.; Yang, Y.Y.; Gao, S.J.; Uyama, H. Injectable biodegradable hydrogels composed of hyaluronic acidtyramine conjugates for drug delivery and tissue engineering. Chem. Commun. 2005, 4312. [CrossRef] 
17. Zhang, Y.; Fan, Z.; Xu, C.; Fang, S.; Liu, X.; Li, X. Tough biohydrogels with interpenetrating network structure by bienzymatic crosslinking approach. Eur. Polym. J. 2015, 72, 717-725. [CrossRef]

18. Fan, Z.; Zhang, Y.; Fang, S.; Xu, C.; Li, X. Bienzymatically crosslinked gelatin/hyaluronic acid interpenetrating network hydrogels: Preparation and characterization. RSC Adv. 2015, 5, 1929-1936. [CrossRef]

19. Naseri, N.; Deepa, B.; Mathew, A.P.; Oksman, K.; Girandon, L. Nanocellulose-Based Interpenetrating Polymer Network (IPN) hydrogels for cartilage applications. Biomacromolecules 2016, 17, 3714-3723. [CrossRef]

20. Matricardi, P.; Di Meo, C.; Coviello, T.; Hennink, W.E.; Alhaique, F. Interpenetrating Polymer Networks polysaccharide hydrogels for drug delivery and tissue engineering. Adv. Drug Deliv. Rev. 2013, 65, 1172-1187. [CrossRef]

21. Dragan, E.S. Design and applications of interpenetrating polymer network hydrogels. A review. Chem. Eng. J. 2014, 243, 572-590. [CrossRef]

22. Lee, J.W.; Kim, S.Y.; Kim, S.S.; Lee, Y.M.; Lee, K.H.; Kim, S.J. Synthesis and characteristics of interpenetrating polymer network hydrogel composed of chitosan and poly(acrylic acid). J. Appl. Polym. Sci. 1999, 73, 113-120. [CrossRef]

23. Wen, C.; Lu, L.; Li, X. Mechanically robust gelatin-alginate IPN hydrogels by a combination of enzymatic and ionic crosslinking approaches. Macromol. Mater. Eng. 2014, 299, 504-513. [CrossRef]

24. Jin, R.; Lin, C.; Cao, A. Enzyme-mediated fast injectable hydrogels based on chitosan-glycolic acid/tyrosine: Preparation, characterization, and chondrocyte culture. Polym. Chem. 2014, 5, 391-398. [CrossRef]

25. Liu, J.; Pu, H.; Liu, S.; Kan, J.; Jin, C. Synthesis, characterization, bioactivity and potential application of phenolic acid grafted chitosan: A review. Carbohydr. Polym. 2017, 174, 999-1017. [CrossRef] [PubMed]

26. Liu, Y.; Wong, C.-W.; Chang, S.-W.; Hsu, S. An injectable, self-healing phenol-functionalized chitosan hydrogel with fast gelling property and visible light-crosslinking capability for 3D printing. Acta Biomater. 2021, 122, 211-219. [CrossRef] [PubMed]

27. Guo, F.; Li, G.; Zhou, H.; Ma, S.; Guo, L.; Liu, X. Temperature and $\mathrm{H}_{2} \mathrm{O}_{2}$-operated nano-valves on mesoporous silica nanoparticles for controlled drug release and kinetics. Colloids Surf. B Biointerfaces 2020, 187, 110643. [CrossRef] [PubMed]

28. Zhou, Z.; Li, G.; Wang, N.; Guo, F.; Guo, L.; Liu, X. Synthesis of temperature/pH dual-sensitive supramolecular micelles from $\beta$-cyclodextrin-poly( $N$-isopropylacrylamide) star polymer for drug delivery. Colloids Surf. B Biointerfaces 2018, 172, 136-142. [CrossRef]

29. Jin, L.; Huang, Q.J.; Zeng, H.Y.; Du, J.Z.; Xu, S.; Chen, C.R. Hydrotalcite-gated hollow mesoporous silica delivery system for controlled drug release. Microporous Mesoporous Mater. 2019, 274, 304-312. [CrossRef]

30. Perioli, L.; Posati, T.; Nocchetti, M.; Bellezza, F.; Costantino, U.; Cipiciani, A. Intercalation and release of antiinflammatory drug diclofenac into nanosized ZnAl hydrotalcite-like compound. Appl. Clay Sci. 2011, 53, 374-378. [CrossRef]

31. Tan, D.; Yuan, P.; Annabi-Bergaya, F.; Liu, D.; Wang, L.; Liu, H.; He, H. Loading and in vitro release of ibuprofen in tubular halloysite. Appl. Clay Sci. 2014, 96, 50-55. [CrossRef]

32. Kong, B.J.; Kim, A.; Park, S.N. Properties and in vitro drug release of hyaluronic acid-hydroxyethyl cellulose hydrogels for transdermal delivery of isoliquiritigenin. Carbohydr. Polym. 2016, 147, 473-481. [CrossRef] [PubMed]

33. Korsmeyer, R.W.; Gurny, R.; Doelker, E.; Buri, P.; Peppas, N.A. Mechanisms of solute release from porous hydrophilic polymers. Int. J. Pharm. 1983, 15, 25-35. [CrossRef]

34. Peppas, N.A.; Sahlin, J.J. A simple equation for the description of solute release. III. Coupling of diffusion and relaxation. Int. J. Pharm. 1989, 57, 169-172. [CrossRef] 